\title{
Reaching Across Worlds: Kanohi ki te Kanohi. A conversation between Anna Hinehou Fleming and John O’Connor
}

\author{
Anna Fleming (Ngāpuhi, Ngāi Tūhoe) and John O'Connor
}

\author{
PSYCHOTHERAPISTS, AUCKLAND
}

\section{Whakarāpopotonga}

Kua tuhia kua kauhautia ngā momo āhuatanga tirohanga Māori e pā ana ki te piringa, e Anna Fleming. Ko te tino ko te whakapuaki tirohanga Māori, nō mai noa rānō nei e whakahau ana i te tino ngākau o te hononga ki te ahurei ngā ariā ā-rōpū pēnei i te whānu, whenua me te wairua. I roto i tēnei kōrero tahitanga a rāua ko John O’Connor, e tūhurahia ana e whanakehia ana e Anna ènei ariā me te nui o ēnei ki te oranga pea mō te katoa, engari pū mō te Māori taketake o Aotearoa.

\begin{abstract}
Anna Fleming has written and presented in diverse contexts on an Indigenous Māori perspective regarding attachment. In particular she has articulated Indigenous Māori perspectives which have always emphasised the vital significance of connections to cultural and collective concepts such as whānau, whenua, and wairua. In this conversation with John O'Connor Anna explores and develops these ideas, and their crucial importance to the wellbeing, perhaps of us all, and in particular, for Indigenous Māori in Aotearoa New Zealand.
\end{abstract}

\section{Introduction}

Anna and John have known each other for several years. Initially Anna was a student at Auckland University of Technology in the Master of Psychotherapy programme, and John supervised her dissertation "Ngā Tāpiritanga", which explored similarities and differences in Indigenous Māori and Western perspectives regarding attachment, and the implications of these for psychotherapeutic practice in Aotearoa New Zealand. Since Anna completed her dissertation, John and Anna have continued to talk together about these rich and complex ideas. On a windy Sunday afternoon in July 2019 Anna and John sat together to explore these ideas further. The result is the interview below. John and Anna invite us to

O’Connor, J., \& Fleming, A. H. (2019). Reaching across worlds: Kanohi ki te kanohi. A conversation between Anna Hinehou Fleming and John O'Connor. Ata: Journal of Psychotherapy Aotearoa New Zealand, 23(1), 77-88. https://doi.org/10.9791/ajpanz.2019.08 
listen in on their conversation with the hope that this might inspire the listener's own thoughts, questions, challenges and ideas.

John: Kia ora Anna, thank you for talking with me. I understand you have been reading quite a lot about what has been happening for children in the care of Oranga Tamariki recently. Given your research regarding a Te Ao Māori perspective on attachment, what has struck you about recent events, particularly events in which tamariki have been removed by Oranga Tamariki from the care of their whānau?

Anna: Kia ora John. The question that always comes up for me when they are uplifting a child, is where is it going to go? We know that there are sometimes reasons why children cannot be within their whānau but if they are being taken from there, what space are they going into and what is the plan for them to be able to come home? Ultimately, I think that is where they need to be; most people would agree with that. I think there needs to be a lot more accountability and a lot more understanding of what the reason is for why we are uplifting a child. We have to be really clear on why that is.

If there are areas that are lacking within that whānau, can we support them, firstly, to be able to look into those and heal those? It feels like such an extreme case to have to take a child away from its mother.

John: I will return to this shortly but just going back a step, my understanding of a lot of your critique of Western perspectives on attachment is that it focuses so much on early interpersonal relational experiences for the infant and that you are largely saying that it is at the expense of recognising the significance of nonhuman attachment. Can you say a bit about that?

Anna: In terms of attachment theory, if we think about it from where it began, most of the early writings around attachment were focused on attachment to the mother or another singular person. It really was not until the seventies, eighties, nineties that I started to find more writing on anybody else: fathers, and then a bit more about sibling attachments as well. Certainly, nothing beyond those personto-person attachments. I found it really hard to find any literature on that although, in saying that, more recently there has been more writing about humans' attachment to the earth.

What I did find consistently in Māori writings were these ideas of connections to the whenua (the land); to people; to people outside of the parenting couple, so to whānau, to grandparents, to aunties and uncles, to hapu and iwi also. The importance of knowing their connections to those things and also understanding the knowledge of certain aspects of Te Ao Māori so, for example, te reo Māori and tikanga Māori. Of course, all of those underpin wairuatanga so that was really consistent throughout Māori themes of development and attachment. I could not really find anything like that in the Western literature that I was reading.

John: In terms of the Western emphasis, starting with John Bowlby, on the importance of the earliest days and months, and even the inutero experience has been explored much more recently in terms of the development of secure attachment, from a Te Ao Mãori perspective, what is your take on the significance of the earliest caregiver roles for infants given that, of course, an infant will not survive if there is 
not at least one person paying close attention to their physical needs and, arguably, their emotional and spiritual needs as well. What would you say Te Ao Māori has to say about that?

Anna: I think the thing to acknowledge first is that the presence of these other attachments to whenua, whānau, hapū, iwi, etc. are not at the expense of attachment to a primary caregiver. So the role of the parent is extremely fundamental in Te Ao Māori for the development of a child. One of the things that I have been learning recently is that when babies are still growing and when the mother is hapu with the child both parents say their whakapapa to the baby as it is growing. Then when the baby is born and they have in the early days that really soft part on their head - the fontanelle - the parents speak into the fontanelle the baby's whakapapa. The idea is that once the skull hardens and that area becomes fused, that information is already in the child's brain.

That, I think, is an example of growing that attachment to the child before it is even born but it also shows the importance of those other connections so the idea that whakapapa is so important for a child to know before it might even have that cognitive ability to understand what it is. I think that is really important in itself. I think the idea that is emphasised within Te Ao Māori is that bringing up children is the integral nature of the whannau, the idea that that child is born into a whānau, it is not just born to its parents; and each whānau member has its own role to play in terms of raising that child. That is something that is still very known and held on to in Te Ao Māori quite strongly.

John: As you tell me about the whakapapa being recited to the infant both inutero when the mother is hapu and also after birth via the fontanelle, I was thinking about the idea of what has been termed implicit relational knowing, how infants learn relational expectations through how they are interacted with in the earliest months and years of life. The idea of whakapapa adds another layer to the idea of implicit relational knowing because it is not only a knowing of how they are being responded to but about their ancestry and the history of what holds them as they grow into life. Is that a fair connection?

Anna: Yes, I think a lot of that is about the taonga - the treasures - that we have now and the strength that we have now comes from the people that came before us. The importance of a child having that knowledge, knowing who their ancestors were before them, the stories that they hold, the achievements that they made, the stories of the whānau, and how that shapes us right through until today, that is incredibly strong knowledge for us as humans.

I was also thinking as we were talking that often those stories stay with us right through our lives; Māori is often described as being an oral language, an oral history, so there are often stories that keep being told over and over. They are often not just reserved for the adults, often children are told these as well and they become a part of their life, a part of their knowing right from day one or preday one.

John: That feels such a rich relational and cultural environment in which to grow oneself. Speaking of the notion of self, what do you think that means for the wider ideas of 
attachment and connection that you are talking about? What does that mean for the notion of how Te Ao Māori might understand or think about what a self is?

Anna: This is something I have thought about a lot because such an overarching theme within Te Ao Māori is that of the whānau, the collective, and not just your immediate whānau; it is also your hapū, your iwi, so what you do as an individual impacts on those wider groups as well. Which can also create quite a pressure on people when you are thinking every little thing that you do can have an impact on so many other people. I think it is a way of keeping people on a right path and creating a bit of boundary. I am often thinking about this myself, how to hold on to my own selfidentity while being part of a collective.

I think that is one of the reasons why I have become quite interested in psychotherapy and working with people in that way, because when people come and see me, yes, I am talking with them but I'm also thinking about them in relation to all those other different groups of people in their life. I also want to help them be able to think about the decisions that they make and the spaces that they move into, such as how do they make a decision that is good for themselves as well as those other people?

John: As you speak my mind goes to thinking about the notion of self in relation to attachment to whenua. I will leave it to you to say your thoughts about how attachment to whenua impacts on the experience of self for Māori. While you are thinking about that, Amanda Dowd is an Australian analyst and she writes quite a lot about the loss of connection for migrants, in particular European migrants and also from other countries coming to the southern hemisphere. She writes from within the Australian context and her emphasis has been more on migrants than on the Indigenous and she has been thinking about what she calls the loss of the background of meaningful containment, by which she means the loss of all our attachments to cultural objects, to cultural knowledge and to geography, to the losses of places of belonging that the migrant experiences in what can be a traumatic experience of moving from one country to another.

Of course, that loss of the background of meaningful containment can be seen as devastatingly impactful for the Indigenous peoples of both Aotearoa New Zealand and Australia in which cultural objects and connection to land has been so profoundly disrupted if not decimated by the early colonial project, and that that continues today. Any thoughts on this?

Anna: It is a different kind of loss, I think, because when I was listening to you say that, I was thinking it is a loss but it is not one that we chose and we still have to live on this land that we have apparently lost which, personally, I think carries a different kind of trauma and we are still having to fight to have that recognised. I am thinking we are sitting in Mangere now and really close by is Ihumātao where they are currently trying to fight for their land, where they have got people trying to develop it at the moment and turn it into houses when, really, that space was incredibly important for Māori. It was a place for huge māra kai, gardens of food; that was where people used to grow so many crops, as food grew so well out there.

This is a struggle that we are still having to see now and in terms of that question 
about how that impacts self, I was thinking this feels like it is an area where this is a real collective thing and I keep thinking about Ihumātao because it is really present but they have a group of people that are living out there at the moment and they are doing that to literally keep the land warm and occupied. They are doing that not only for themselves but also the generations to follow them, so while I imagine it is an individual decision of many to do that, in their minds I know from the people that I have talked to out there, it is very much a collective decision as well to be able to protect that land for the future because they do not want it to be taken away from them as it was in 1863 .

John: That is a very pertinent and contemporary example of the way in which that dispossession from connection and attachment to land continues and how decimating this is.

Coming back to this idea of whenua and its relation to the experience of self, if we think about the kind of urbanisation that happened in the 2oth century when Māori largely moved from rural environments to urban environments. In terms of the psychological and spiritual impact of that, attachment to land and the disruption of that through urbanisation, how do you see that impacting on Māori psyche?

Anna: I think it has probably been one of the largest factors in terms of how this has disrupted Mãori and our progression. There is a huge percentage of people who live away from their papa kāinga, where their marae is. If you think about your marae and particularly the whenua that the marae sits on as being the container of your knowledge, the further you are away from that the harder it is to access and even, for example, the difficulty in being able to go to that place and work the land, grow food there, even look after your urupā. Many people have urupā cleaning days but I know that a lot of people, a lot of my friends have said often they will only go and do that maybe once a year whereas if you are living in that area, you might be doing it several times a month.

One of the things that I have read, I think it was a Mason Durie quote, was that the impact of Māori not being able to physically work their land has taken a huge toll on our wairua because wairua is so intrinsically connected with land, so when you are not able to access it, live on it, be with it as much as you can, then that has quite a negative impact. I think the reality is most people have had to move away from those spaces to be able to find work and it has not been viable to live on many of our marae anymore; there is a cost that comes with that.

John: What I think of as you say that is how intimately engaged with the land all Indigenous cultures have been, including my own Celtic ancestors, and how much urbanisation and globalisation pulls us more and more to a disconnect with the land. I then think of the environmental crisis that our world faces at the moment and I wonder whether you see any connection between the dispossession for Indigenous Māori, the impact of that on other cultures including European and non-European non-Indigenous cultures that live on this land now, and what Te Ao Māori might have to offer us in relation to the environmental crisis we now face.

Anna: For Māori, we see Papatūānuku as being our mother - everything comes from her. 
I know that it is so similar in so many other cultures as well - that idea of mother being the earth. That personification of land as mother makes sense to me when we are thinking about our connection with her. I think a lot of it has come down to ease, so not even that long ago people would grow their own food quite easily but so many people just do not do that anymore. I think also what we forget, there is a lot that gets lost in those little things, so when people are growing food, they do not just do it by themselves; they often are working the land with other people, with their whānau, with neighbours and then they share out that food with other people. It has had an impact, I think, on those kinds of connections as well.

I think, too, when you become so disconnected from something, I think in a way we have almost forgotten how to care for the land and my sense is that that is what is underlying a lot of what we are seeing with how we are getting into more and more of a hole with how we are treating the earth because, from what I am seeing, there is just a lot less care, a lot less attention. We are still having to convince people that climate change is actually a thing, when I think it has been pretty obvious over the years. I guess when you become disconnected from something, it is easy to not see it.

John: Tragically so. On a slightly different tack, just going back to this idea of attachment to people, attachment to all aspects that you have spoken to around whenua, wairua, tikanga Māori, mātauranga I'm reminded of the film “Once Were Warriors”. Ann Salmond talks about this in her book, Tears of Rangi, and that when that movie came out in the 1990 s it was used by some to help to construct Māori as inherently violent, and there were even researchers attempting to establish whether there was a genetic predisposition to violence within Māori, and to violence amongst Mãori. What is your response to that research which, of course, has now been completely debunked?

Anna: Apart from laughing. I think I always go back to the fact that there is nothing in our marae or in our stories that talks about that kind of violence so there is nothing in our own reflections. But also I think last week I was reading about some observations that early, early, early visitors to Aotearoa made and they basically said that they had never seen a group of people so attentive to their children, so caring of their children. They noticed that males were as involved with the raising of children as females were and also the community raising of children was really apparent as well.

For me, there is something really significant that happened between that time and the 1990 s when this "warrior gene" thing came out, there is something that happened in there that really impacted how Māori worked within their whānau. Personally, I think it has been the effects of colonisation because the way that we raised our babies, we were not able to do that in the same way, and all the other ways that we also know that our knowledge was interrupted meant that we could not practise the way that we had been for generations and generations. What does somebody do when they cannot behave the way that they always have? They have to find other ways and maybe some of them were not so good.

John: If we grapple with the difficult reality of violence, particularly to children, and the disproportionate rate of violence to children and how that is reflected in the recent 
news stories we see emanating in relation to that violence amongst Māori, which we referred to at the beginning of this conversation in relation to the uplifting of tamariki from their whanau what is your thinking about what contributes to that violence and our and the state's response to that?

Anna: My thinking, when I saw the stories come out this week, which I do not necessarily think are new, was, what kind of support had that whānau been given? In particular what practical supports were the whanau given before the decision was made to uplift their pèpi. In one of the recent media stories, the whanau and mama had wanted Mama and baby to move to a support house so that they could be together and be supported by house staff. Were the whānau involved in these decisions? Was it maternal and paternal whānau, were hapū and iwi considered? I feel like uplifting a child is a really, really last case scenario and we should be doing everything that we can before that to put as much support into the whānau as we can. I think we need to start thinking a bit more broadly around what that support means so I do not think it necessarily just means sending a parent off to a parenting course. I think we need to be thinking outside the square but when you are working with Māori whānau you have to think about what is going to work for that whānau. Maybe it is that somebody goes into their home to actually see how they work and see what they are feeling like, what they need within the home themselves. That maybe it is about giving them time to go back to their marae, to speak with other people from their hapu and iwi - to have those kinds of people support them as well. So, it is not just strangers coming into the house.

I absolutely know that nobody wants children to be in danger but the way that we support people to look after their children, I think that does need to change.

John: To me, I can see a direct link between that and your research around Te Ao Māori perspectives on attachment and connection, and how disconnection contributes to violence. But to put it in your own words, what is the relationship you see between the loss of connection to the Te Ao Māori concepts and relationships we have been talking about and how that produces the kind of violence we see coming across our television screens?

Anna: Personally, I think that what underlies a lot of anger is actually hurt and pain and often fear. I think my work in psychotherapy is to try to deal with that, with the idea that if we can deal with that, that will filter up to the anger. My thinking is that Māori in Aotearoa have experienced a huge degree of hurt and pain that has not been of their doing. What we are seeing now is a reaction to that, generations and generations down, why wouldn't it be? Even though it might have been our greatgreat-grandparents that were taken away from their land or smacked at school for speaking their reo. That trauma stays with them and then they parent their children holding on to that trauma, and it carries on and it carries on. My sense is that that pain and that hurt from the loss of those connections does have a lot of impact in terms of how people behave in the present, just as it did then.

John: Given that direct connection between the loss, dislocation, and decimation of Indigenous Mãori connections and how violence emerges out of that unacknowledged loss and grief, when you think of the research that you have 
undertaken, if there is something or some things that you would really like psychotherapists to take on in terms of your research and its implications for our psychotherapy clinical practice, what would those things be?

Anna: I was thinking then as you were saying "lost" and "gone" and I thought, thankfully, these things are not lost and gone. Our ancestors worked really hard in their own ways to make sure that these things were not gone. Some of them have come really close but I think a lot of what is important now is actually holding that space. Nobody can make anyone do it, but it is about holding the space for Māori to feel they can and are able to reconnect with these things if they feel a disconnection. I think as a psychotherapist, for me, and also in my own therapy was actually knowing that my therapist acknowledged me as Māori and always held that space open for me to be able to talk about what that meant. That was really difficult to begin with because of my own history but I always knew in the back of my mind that it was there and I could always bring that up if I wanted to.

I think sometimes people have a difficulty in that, especially if they are not Māori, they feel like, is it okay for me to voice this? Is it okay for me to even be curious about this? My encouragement would be actually, yes, it is okay because it is really powerful to acknowledge somebody in their self and to acknowledge and to say to them, "What do you think about your whenua? Where do you come from?" Just asking open questions like that and then they are the one that can make those connections and maybe go back to those spaces. I think being not afraid to be curious and to be inquisitive and interested is something that is really helpful.

John: On a slightly different note, but I think it links to all of this, I have heard a lot from students and colleagues who neither identify as Māori nor as Pākehā, and I know the meaning of Pākehā has many different layers to it and can be quite controversial. In the way that it is often used in Aotearoa by people like myself of English and Irish heritage, it is often used as part of a way to construct an identity that is for people of British origin. People who have come to Aotearoa New Zealand with ancestries and histories that are nonBritish in origin and not Māori often feel as if they are excluded by the word "biculturalism" and the idea of bicultural. I want to link this to your ideas around attachment and the challenge for psychotherapists just to think about that first. Any thoughts about that?

Anna: Yes, and it might not be a popular one! I was talking to somebody once and I am not sure if this is entirely the case but I will say it anyway. Pākehā is an Indigenous word that has been given to describe the people that came to live in this place and that has not happened very often in other Indigenous cultures. There has not been an Indigenous word for those kinds of people. The way that I look at it is actually that is something quite significant, that a Māori word has been given to those people coming here and I think there is something in that and also that the Treaty was signed initially in way of a kind of partnership.

I am not Pākehā but when I see that word, how I would like it to be taken is actually this is something that has been given or offered in a way that has not necessarily happened in other places where there have been Indigenous and nonIndigenous people. 
John: Are you saying in that, that you are inviting all people who live in Aotearoa New Zealand who are nonMāori - whether they come from British origins or from other origins like Asian, Sri Lankan, Indian, eastern European, American, Australian, etc. - whoever it is or whatever origins or ancestries we bring, that the word "Pākehā" is a word that we are all invited to step into in relation to Māori?

Anna: Potentially. I think the other way that we can maybe think about it is Pākehā has been a word that has evolved from that time of Europeans coming to Aotearoa in the first instance. I know the other word is Tauiwi, which means people from afar. I think what is more important is acknowledging that people have chosen to live in Aotearoa and I think that there are responsibilities that come with that choosing to be here.

John: What I was thinking there was that, as you were saying that, and I was resonating with it, that I think this is more of a challenge for people like me of British origin than for Māori to welcome Tauiwi in terms of having a voice in the bicultural conversation rather than feeling like it is only people like me of British origin that get to have a voice in relation to Indigenous Māori. We all have, as you say, a responsibility to have a voice in the relationship in relation to the Indigenous of this country. Wherever we are from, however long we have been here, acknowledging that what that voice could be might be quite different depending on our ancestral history. I think it is a very different experience for me as a person of British and Irish origin to have a relationship and a voice in relation to the Indigenous than someone who is a new immigrant, say, from India, that is a very different relationship that they bring. They of course may bring memories and histories of other colonial experiences from their own ancestral origins, but they do not bring the history of colonisation in Aotearoa New Zealand to that relationship in the way I do.

Anna: It is just as valuable and I think it adds to our diversity. I think the other thing is that often it's really hard when we are thinking about our history. It brings up its own different types of pain for people and that is the reality and it is more important to do that, to be able to face into that and feel it than pretend it has not existed. I think when we pretend it hasn't existed, that is when it comes out in more unpredictable ways.

John: To complete the circle, what would you say are the challenges in relation to your attachment research for a psychotherapist like me who has British ancestry and has been in Aotearoa New Zealand for several generations? When I am being a therapist in relation to the attachment ideas of Te Ao Māori? And are there any similar or different challenges for someone who is Tauiwi but not of British origin, who may be a newer immigrant, trying to get their minds and hearts around the relationship to the Indigenous and Te Ao Māori ideas, when they are engaged in clinical practice? I recognise this is quite a big and tricky question, so whatever comes to mind.

Anna: I think there are two things to think about and it probably applies to both sets of people. The first is in acknowledging and prioritising these connections for Māori. Understanding that the relationships to land, the relationships to knowledge, the 
relationships to wider groups of people like hapū and iwi actually are important. I think the second part is giving that space, and you can only give it space if you recognise its importance. My sense is that the first needs to happen and maybe depending on which of those two people you are, if you are Pākehā or Tauiwi, the way that you might think about those connections might be different based on your own stories and your own history. That is my sense, that first, there needs to be an acknowledgement and an importance recognised in it and then, secondly, you give it space when you are working with tangata whaiora.

John: Psychotherapy in Aotearoa New Zealand remains dominantly influenced by Western ideas regarding the nature of psyche, often very intrapsychic and internally focused. Gradually with the research you have undertaken, and others such as Margaret Morice's research around relational concepts from Te Ao Māori including wairuatanga, manaakitanga, kaitiakitanga, etc., Jo Reidy's work on mana enhancing psychotherapy, Alayne Hall's work on trauma and whakapapa, and Wiremu Woodard's work on the nature of the void that has been created through colonisation and the addressing of that in psychotherapy, gradually the Indigenous voice is starting to infuse psychotherapy practice in this country. In terms of the development of psychotherapy in this context, what do you think is our next challenge?

Anna: I would like it to be that this knowledge is not just seen to be used by Māori. Absolutely by Māori for Māori, and if you have a Mãori client I would really be expecting that you be reasonably cognisant of some of the mātauranga that you have just mentioned. Also that our Pākehā and Tauiwi practitioners can access this knowledge on their own; that they can do the readings for themselves; that they can become more knowledgeable about it for themselves; that they feel like they can take that responsibility for themselves so that it is not just seen as being, "that's the space for Māori”. I would love to see more people involved with Te Ao Mãori and to be able to recognise the benefits that that can bring people. So that Māori spaces are not just seen as for Māori only. I want to be quite specific about that. There is a way that they need to be prioritised for Mãori but also that I do not want other people to feel scared of those spaces or that they need to stay away. I think there is a way that people can engage with them without taking them over, if that makes sense.

John: It seems to me you are encouraging all psychotherapists to engage with Te Ao Māori, with mātauranga, to be in relationship with Te Ao Mãori, from the specific position each of us bring to this relationship, and that each relationship will be different depending on what of our own histories and ancestries we bring. But that the more we engage, the richer the relational dynamics, which brings us full circle with your relational research.

The New Zealand Association of Psychotherapists (NZAP) itself is an association whose different aspects are being reviewed at the moment and we are just beginning to review what the next step might be in the bicultural relationship between NZAP and Waka Oranga, between Māori and nonMāori, in relation to the Association and its structures and organisations. Any preliminary thoughts on the 
direction, the next steps, from an organisational or Association perspective?

Anna: I think mainly what is coming up for me is not expecting spaces like Waka Oranga or Māori spaces to run exactly as they would in a Pākehā organisation. We cannot just take how NZAP runs and overlay that on top of Waka Oranga. That is just not going to work, it is not how we roll, so we have to be given the space to develop our own pathways. I think that we have been given that in a sense and in my mind I am thinking about He Ara Māori. The fact is that Waka Oranga has really only been in existence for the last 11 years, so developing our own practices takes time and it takes a lot of energy. I think ways that we can support that, whether it be financially or with time, is all really important at the moment so that we can develop our own way of being because we are really creating something from the ground up. I think acknowledgement of that and patience with that is what's needed at the moment.

John: Kia ora, Anna. We have reached the end of our körero. It has been lovely to talk with you.

Anna: You, too. Ngā mihi, John.

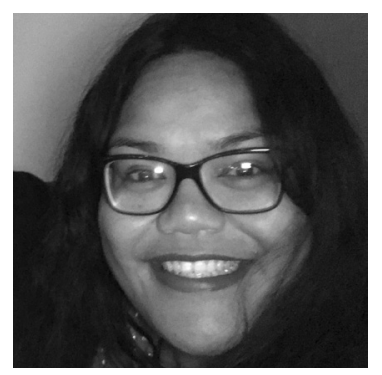

Anna Hinehou Fleming (Ngāpuhi, Ngāi Tūhoe) is a registered psychotherapist, serves on te Rūnanga o Waka Oranga, National Collective of Māori Psychotherapy Practitioners and is a provisional member of the New Zealand Association of Psychotherapists. Anna has worked in various social and health services with individuals and whānau for over 14 years. In 2017, she graduated with a Master of Psychotherapy with first class honours. Her therapeutic approach combines her working and personal experiences with a focus on attachment and developmental theory particularly from a Māori perspective. This focus on Indigenous health informs Anna's current role as Counsellor for Māori at Auckland University of Technology, and her growing community practice in Tāmaki Makaurau. Contact details: fleming.anna@gmail.com.

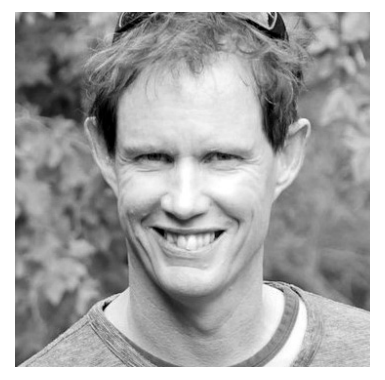

John O'Connor has worked as a counsellor and psychotherapist for over 30 years, and has a wide range of clinical experience, particularly in working with clients with severe trauma histories, in providing group psychotherapy, and in working cross-culturally. $\mathrm{He}$ is a former Director of Youthline Counselling Service (Auckland) and the Human Development and Training Institute. He also formerly worked at Segar House (which is part of ADHB Mental Health Services) and was a founding member of the therapeutic team at Segar which developed a residential treatment service (currently operating as a day programme) for clients with personality disorder diagnoses. He has worked as a lecturer at the Auckland 
University of Technology within the Psychotherapy Discipline since 1999 and was formerly Programme Leader of the Master of Psychotherapy (adult programme) at AUT. He is coeditor of Ata: Journal of Psychotherapy Aotearoa New Zealand. John is an associate member of Waka Oranga. John also conducts a private practice in Mangere Bridge. John is currently a candidate in training as a Jungian Analyst with the Australia New Zealand Society of Jungian Analysts and is undertaking his $\mathrm{PhD}$ exploring the discourses underpinning bicultural clinical encounters in Aotearoa New Zealand. Contact details: johnnygj@xtra.co.nz. Phone 021-899-261. 